\title{
Ovothiol-A Isolated from Sea Urchin Eggs Suppress Oxidative Stress, Inflammation, and Dyslipidemia Resulted in Restoration of Liver Activity in Cholestatic Rats
}

\author{
Nada Mahmoud Khalil Madany 1(D), Mohamed Refaat Shehata ${ }^{2}$ (D), Ayman Saber Mohamed 3,*(D) \\ 1 Biotechnology department- Faculty of Science- Cairo University- Giza-Egypt; nadam.khali195@gmail.com (N.M.K.M.); \\ 2 Chemistry Department, Faculty of Sciences, Cairo University- Giza- Egypt; mrshehata_05@ @otmail.com (M.R.S.); \\ 3 Zoology Department - Faculty of Science - Cairo University -12613, Giza, Egypt; ayman81125@cu.edu.eg (A.S.M.); \\ * Correspondence: ayman81125@cu.edu.eg;
}

Scopus Author ID 56564677600

Received: 13.10.2021; Revised: 18.11.2021; Accepted: 20.11.2021; Published: 9.12.2021

\begin{abstract}
Cholestasis is dropping in bile flow, leading to the intrahepatic bulk of bile acids and other poisonous compounds with the progression of liver pathology, including hepatocellular injury and fibrosis. Ovothiols extracted from sea urchin display unusual antioxidant properties due to the peculiar position of the thiol group on the imidazole ring of histidine. The present study aims to evaluate the anti-fibrotic effect of Ovothiol-A in rats. 28 rats were allocated randomly into 4 groups: Sham, BDL, and BDL + Ovothiol A (500 mg/kg). All rats were treated for 7 days. Oxidative stress biomarkers, liver functions, lipid profile, and histology were all examined. The results revealed that BDL operation induced oxidative stress in rats, which negatively impacted liver functions, as confirmed by the histopathological examination. Ovothiol-A has been shown to lower oxidative stress and enhance lipid profile, resulting in considerable improvements in most biochemical markers. Also, histopathological examination showed an improvement in the liver architecture of the treated group compared to the BDL group. Ovothiol-A protects the liver against toxicity results from cholestasis in rats.
\end{abstract}

Keywords: Ovothiol-A; bile duct ligation; cholestasis; sea urchin- natural products.

(C) 2021 by the authors. This article is an open-access article distributed under the terms and conditions of the Creative Commons Attribution (CC BY) license (https://creativecommons.org/licenses/by/4.0/).

\section{Introduction}

Cholestasis is known as dropping in the flow of bile, which leads to the intrahepatic bulk of bile acids with the progression of liver pathology, including hepatocellular injury and fibrosis [1]. Liver fibrosis is a hypothetical reaction to ongoing tissue damage that is linked to the majority of chronic inflammatory illnesses [2]. Chronic liver injury occurs as a result of a long-term wound-healing response, resulting in liver fibrosis, leading to an overabundance of extracellular matrix (ECM) proteins, which promotes fibrogenesis and, as a result, cirrhosis [3]. Fibrosis is characterized by the invasion of inflammatory cells, the activation of inflammatory cytokines, the apoptosis of hepatocytes, and the proliferation of nonparenchymal cells producing, primarily hepatic stellate cells (HSCs). Proliferation, migration, and contractility are all characterized by the active HSCs, as is their resistance to apoptosis [4]. Chronic liver injury causes vascular architectural distortion and liver malfunction, which is defined by liver fibrosis and its advanced stage cirrhosis [5]. 
Bile duct ligation (BDL) is a well-known method for causing cholestatic injury and periportal biliary fibrosis. BDL consists of a doubly ligated bile duct sectioned between two ligatures. Bile duct obstruction increases biliary pressure, mild inflammation, and cytokine secretion by biliary epithelial cells, consequently generating cholestasis. Increased systemic oxidative stress and damage to key organs such as the brain, kidney, liver, heart, and gut result fromile duct ligation [6]. Chronic liver illnesses are a major public health concern around the world. So the need to develop more efficacious products and benefits for humanity to treat or overcome the side effects of most of the confirmed drugs has stimulated a great interest from the nutraceutical and pharmaceutical industrial field to discover new natural products from less explored sources.

There has been an increasing interest in the marine environment in recent years which has a higher biodiversity than the terrestrial environment [7]. Many licenced pharmaceutical medicines derived from marine natural resources [8]. Sea urchins are traditional model organisms in developmental biology, and it contains many pharmaceutical products that can be extracted from them [9]. From these compounds, ovothiols that have the unique location of the thiol group on the imidazole ring of histidine procure exceptional antioxidant capabilities [10]. Ovothiol-A, purified by sea urchin eggs, was shown to be an effective treatment for in vitro liver fibrosis and induce autophagy in human hepatocarcinoma cell lines[11]. So our present study aims to investigate the protective effect of Ovothiol-A against cholestasis induced by bile duct ligation in rats.

\section{Material and Methods}

\subsection{Chemicals.}

All drugs, chemicals, and solvents were purchased from local companies, and they were of the highest purity and analytical grade

\subsection{Isolation of Ovothiol-A from sea urchin eggs.}

Ovothiol-A was isolated according to the method of Russo et al. [12]. First of all, we injected about $1 \mathrm{ml}$ of potassium chloride $(\mathrm{KCl}$ ) into sea urchin to its eggs then put the sea urchin on the surface of seawater. Collect the eggs of sea urchins, centrifuge at 2000 RPM for 10 mins, and discard the supernatant. In ethanol-1M $\mathrm{HCl}$ (80:20), sea urchin eggs were homogenized then stirred for $12 \mathrm{hrs}$. The homogenate was centrifuged at 6000 RPM for 15 min. The supernatant was collected, and ethanol evaporated in a rotatory evaporator at $40 \mathrm{oC}$. The aqueous solution was extracted 3 times with ethyl ether; then the alumina column was used for separate peroxide. The aqueous layer loaded onto a Dowex 50WX2 column $(1 \mathrm{~cm} \times 22$ $\mathrm{cm}$ ). Water, $0.1 \mathrm{M}$, and $0.5 \mathrm{M} \mathrm{HCl}$ are used in order of elution. After that, the column was eluted with $4 \mathrm{M} \mathrm{HCl}$. In the 200-350 nm range, the collected fractions were spectrophotometrically monitored. Fractions with an ovothiol-like UV spectrum were collected, condensed to a small volume, and oxidized to Ovothiol disulfide (Figure 1) in the presence of air for $4 \mathrm{~h}$ at $\mathrm{pH} 8$. After acidification to $\mathrm{pH} 2$, the sample was re- chromatographed on the same Dowex column. Fractions exhibiting the UV spectrum of ovothiol were collected and taken to dryness, affording a colorless, glassy solid $(2.5 \mathrm{mg})$.

\subsection{Experimental animals.}


Male Wistar albino rats (Rattus norvegicus) (100-120 g) were used in all experiments. The rats for any experiment were selected from similar age groups ( \pm 1 week) and weight $( \pm 2$ g). Animals were housed in polycarbonate boxes with steel-wire tops and bedded with wood shavings. They were supplied with a standard laboratory diet and water and libitum. The animals were kept under fixed conditions of housing and handling. All the experimental procedures were carried out under international guidelines for the care and use of laboratory animals.

\subsection{Ethical consideration.}

The Cairo University approved experimental protocols and procedures used in this study, Faculty of Science, Institutional Animal Care and Use Committee (IACUC). All the experimental procedures were carried out following international guidelines for the care and use of laboratory animals.

\subsection{Acute toxicity study $\left(L D_{50}\right)$.}

Acute oral toxicity testing was done in accordance with OECD guideline 420 for chemical testing [13]. For acute toxicity experiments, twelve male Wistar albino rats (Rattus norvegicus) were employed. The rats were separated into two groups, each with six animals: control and test. The rats were administered orally with Ovothiol-A at dose levels of 5000 $\mathrm{mg} / \mathrm{kg}$. Normal control rats received the same amount of vehicle (distilled water). Rats were observed for 24 hours after extract administration and then for the next fourteen days. The rats were observed for signs of toxicity, morphological behavior, and mortality.

\subsection{Induction of liver fibrosis.}

Bile duct ligation protocol was performed according to the method described by Vogel and Vogel [14]. Laparotomy was performed under antiseptic conditions. A midline incision in the abdomen was made, exposing the muscle layers and the linea alba, which was then incised over a length corresponding to the skin incision. The duodenum was then dragged down to expose the common bile duct, which runs practically straight from the liver's hilum to its entry into the duodenum. A blunt aneurysm needle was put beneath the designated segment of the duct, carefully peeling the pancreas away, and the duct was separated with two cotton thread ligatures. The peritoneum, muscle layers, and skin wound were closed with cotton stitches. In sham-operated rats, an abdominal incision was made without a ligation.

\subsection{Experimental design.}

28 male Wistar rats were allocated randomly into 4 groups as follow:

Sham: had an opening in their abdomen with no ligated bile duct, then administrated distilled water for consequence seven days.

BDL: had an opening in their abdomen with the ligated bile duct, then administrated distilled water for consequence seven days.

Ovothiol-A: had an opening in their abdomen with the ligated bile duct, then administrated Ovothiol-A (500 mg/kgm) for consequence seven days

2.8. Animal handling and specimen collection. 
At the end of the experimental period, rats were euthanized with sodium pentobarbital overdose $(100 \mathrm{mg} / \mathrm{Kg})$ [15]. In centrifuge tubes, blood was obtained. The liver was dissected, blotted using filter paper to eliminate any blood remains, and then separated into two halves. The first half was kept at $-80^{\circ} \mathrm{C}$ to determine oxidative stress indicators in the liver. For histological investigation, the second half was fixed in $10 \%$ formal saline [16].

\subsection{Biochemical parameters.}

The levels of serum aspartate aminotransferase (AST), alanine aminotransferase (ALT), total serum protein, serum albumin, alkaline phosphatase activity (ALP) serum total bilirubin, and $\gamma$-glutamyltransferase (GGT), total lipids, triglycerides, total cholesterol, lowdensity lipoprotein, and high-density lipoprotein were determined using Bio-diagnostic assay kits according to the manufacturer's instructions (Giza, Egypt).

In ice-cold $0.1 \mathrm{~mol} / \mathrm{L}$ Tris-HCl buffer, liver tissue was homogenised $(10 \% \mathrm{w} / \mathrm{v})(\mathrm{pH}$ 7.4) [17]. The homogenate was centrifuged for 15 minutes at $40^{\circ} \mathrm{C}$ at $3000 \mathrm{RPM}$, and the supernatant was utilized to evaluate oxidative stress indicators. Malindialdehyde (MDA), reduced glutathione (GSH), catalase (CAT), superoxide dismutase (SOD), and glutathione-Stransferase (GST) were determined according to the manufactures instructions using Biodiagnostic kits (Giza, Egypt)

\subsection{Histopathologic study analyses.}

Liver tissues were fixed in $10 \%$ formal saline, embedded in paraffin sectioned and stained with hematoxylin, eosin,nd Masson Trichrome stain for histological assessment utilizing a light microscope [18].

\subsection{Statistical significance.}

All data were analyzed by analysis of variance (ANOVA) followed by the Duncan multiple range test when the F-test was significant $(p<0.05)$. All analyses were performed using the Statistical Package for Social Sciences (SPSS) software in a PC-compatible computer.

\section{Results and Discussion}

\subsection{Determination of $L D_{50}$.}

None of the rats dead after receiving Ovothiol-A at the higher dose $(5000 \mathrm{mg} / \mathrm{kg})$. As a result, the single fatal dose of Ovothiol-A, which kills half of the animals (LD50), was estimated to be greater than $5000 \mathrm{mg} / \mathrm{kg}$. One-tenth of the suggested LD50 was designated the median effective dose $(500 \mathrm{mg} / \mathrm{kg}$ body weight orally).

\subsection{Liver function markers.}

The liver is a radical organ with plentiful functions. Elimination of multiplied potentially poisonous xenobiotics, including endogenous metabolites, drugs, and toxins, is a prime function [19]. Cholestasis leads to progressive liver injury culminating in cirrhosis and failure of the liver [20].

Data shown in Table 1 revealed that serum ALT, AST, ALP, GGT, albumin, direct bilirubin, indirect bilirubin, total proteins levels increased significantly $(p<0.5)$ in BDL rats 
than Sham group. These harmful alterations in liver enzyme levels suggest a loss of tissue integrity, resulting in hepatocyte apoptosis and necrosis [21,22]. They also reflect the poisonous effect of bile acids on the liver and the severity of hepatic injury in cholestasis. Albumin is solely synthesized in the liver. Albumin is the most significant protein in plasma produced by the liver, and it's also a good indicator of how well the liver is working [23]. Our study revealed that the serum albumin concentration of BDL rats decreased. This drop-in serum albumin levels could be linked to hepatic dysfunction, which is caused by the toxic effects of bile salts on liver cells [25]. The increment in serum globulins concentration in our present study might be due to the more severe impairment of albumin formation in the liver, which attempts by the body to compensate with an increment output of beta and gamma globulins, especially gamma from the spleen [26]. The serum bilirubin level is one of the most sensitive measures for diagnosing hepatic disorders. Conjugated and unconjugated bilirubin have the most significant poisonous effect during cholestasis [27]. The significant degeneration of hepatocytes and blockage of the bile ducts which results from BDL leads to a significant increase in the total serum bilirubin and direct bilirubin levels [28]. Increased plasma direct bilirubin levels after BDL may be attributed to bilirubin flowing out of cells due to cell damage caused by a bile flow obstruction. [29].

Otherwise, the administration with Ovothiol-A orally caused a significant decrease ( $p$ $<0.5$ ) in the levels of the previous parameters (Table 1). A previous study showed that Ovothiol-A has antiproliferative action in hepatocarcinoma cell lines via an autophagic mechanism [12]. The antiproliferative activity of Ovothiol-A was confirmed in the current study by restoration of liver enzymes level near the normal range and restoring the protein synthesis function of the liver.

Table 1. Protective effect of Ovothiol A on liver functions of bile duct ligated (BDL) rats.

\begin{tabular}{l|c|c|c}
\multirow{2}{*}{ Parameter } & \multicolumn{3}{|c}{ Groups } \\
\cline { 2 - 4 } & Sham & BDL & Ovothiol A \\
\hline AST $(\mathrm{U} / \mathrm{ml})$ & $7.37 \pm 0.53^{\mathrm{a}}$ & $36.42 \pm 1.96^{\mathrm{c}}$ & $29.13 \pm 2.94^{\mathrm{b}}$ \\
\hline ALT $(\mathrm{U} / \mathrm{ml})$ & $7.17 \pm 0.70^{\mathrm{a}}$ & $64.05 \pm 7.93^{\mathrm{c}}$ & $37.17 \pm 1.51^{\mathrm{b}}$ \\
\hline ALP $(\mathrm{U} / \mathrm{L})$ & $108.32 \pm 8.23^{\mathrm{a}}$ & $284.52 \pm 20.04^{\mathrm{c}}$ & $190.89 \pm 21.17^{\mathrm{b}}$ \\
\hline GGT(U/L) & $1.43 \pm 0.18^{\mathrm{a}}$ & $2.40 \pm 0.06^{\mathrm{c}}$ & $1.89 \pm 0.18^{\mathrm{b}}$ \\
\hline TP $(\mathrm{g} / \mathrm{dl})$ & $7.25 \pm 1.33^{\mathrm{a}}$ & $8.96 \pm 0.46^{\mathrm{a}}$ & $8.19 \pm 0.39^{\mathrm{a}}$ \\
\hline Albumin $(\mathrm{g} / \mathrm{dl})$ & $4.14 \pm 0.36^{\mathrm{a}}$ & $3.65 \pm 0.20^{\mathrm{a}}$ & $4.01 \pm 0.19^{\mathrm{a}}$ \\
\hline Globulins $(\mathrm{g} / \mathrm{dl})$ & $2.74 \pm 0.93^{\mathrm{a}}$ & $5.28 \pm 0.46^{\mathrm{b}}$ & $4.08 \pm 0.39^{\mathrm{ab}}$ \\
\hline IB $(\mathrm{mg} / \mathrm{dl})$ & $1.17 \pm 0.08^{\mathrm{a}}$ & $4.95 \pm 0.39^{\mathrm{c}}$ & $2.14 \pm 0.04^{\mathrm{b}}$ \\
\hline $\mathrm{DB}(\mathrm{mg} / \mathrm{dl})$ & $0.93 \pm 0.22^{\mathrm{a}}$ & $2.53 \pm 0.12^{\mathrm{c}}$ & $1.64 \pm 0.08^{\mathrm{b}}$
\end{tabular}

Values are given as mean \pm SE for 7 rats in each group. Each value not sharing a common letter superscript is significantly different $(\mathrm{p}<0.05)$.

\subsection{Lipid profile markers.}

The liver is the primary tissue for lipoprotein generation and clearance; it absorbs fatty acids and cholesterol from peripheral tissues and food, bundles them into lipoprotein complexes, and releases them into circulation [30]. Data shown in Table 2 revealed that total serum lipids, triglycerides, total cholesterol, and low-density lipoprotein levels increased significantly $(p<0.5)$ in BDL rats than Sham group in contrast with serum high-density lipoprotein. The observed hyperlipemia could result from increased plasma free fatty acids from accelerated lipolysis [31].

Otherwise, the administration with Ovothiol-A orally caused a significant decrease ( $p$ $<0.5$ ) in all lipid profile levels in contrast with HDL (Table 2). These findings suggest 
antiatherogenic effects of ovothiol A's potential and therapeutic potential in illnesses connected to dyslipidemia [32].

Table 2. Protective effect of Ovothiol A on lipid profile of bile duct ligated (BDL) rats.

\begin{tabular}{l|c|c|c}
\multirow{2}{*}{ Parameter } & \multicolumn{3}{|c}{ Groups } \\
\cline { 2 - 4 } & Sham & BDL & Ovothiol A \\
\hline Total lipids (mg/dl) & $65.74 \pm 12.55^{\mathrm{a}}$ & $197.73 \pm 32.54^{\mathrm{b}}$ & $136.20 \pm 12.86^{\mathrm{b}}$ \\
\hline Total cholesterol $(\mathrm{mg} / \mathrm{dl})$ & $53.18 \pm 6.33^{\mathrm{a}}$ & $186.00 \pm 15.76^{\mathrm{c}}$ & $109.42 \pm 2.16^{\mathrm{b}}$ \\
\hline Triglycerides $(\mathrm{mg} / \mathrm{dl})$ & $63.22 \pm 3.49^{\mathrm{a}}$ & $111.37 \pm 7.44^{\mathrm{b}}$ & $78.40 \pm 3.49^{\mathrm{a}}$ \\
\hline HDL-C $(\mathrm{mg} / \mathrm{dl})$ & $19.67 \pm 1.45^{\mathrm{c}}$ & $4.12 \pm 0.75^{\mathrm{a}}$ & $8.44 \pm 0.74^{\mathrm{b}}$ \\
\hline LDL-C $(\mathrm{mg} / \mathrm{dl})$ & $50.88 \pm 4.96^{\mathrm{a}}$ & $325.12 \pm 29.35^{\mathrm{b}}$ & $86.51 \pm 6.10^{\mathrm{a}}$
\end{tabular}

Values are given as mean \pm SE for 7 rats in each group. Each value not sharing a common letter superscript is significantly different $(\mathrm{p}<0.05)$.

\subsection{Oxidative stress markers.}

Oxidative stress-induced tissue injury is a famed phenomenon associated with cholestasis [33]. Table 3 revealed that MDA and nitric oxide levels increased significantly in BDL rats than Sham group, while GSH, CAT, GST, and SOD levels decreased significantly ( $p$ $<0.5$ ). Increased MDA levels indicate increased lipid peroxidation, which can lead to tissue damage [34]. Cholestasis raised the concentration of bile acids in hepatocytes, causing mitochondrial toxicity and overproduction of reactive oxygen species (ROS) [35]. Excessive ROS produced during cholestasis can cause oxidative damage to biological macromolecules, resulting in depletion in the antioxidant systems include GSH, CAT, GST, and SOD [36]. At the same time, the release of nitric oxide (NO) and nitrosative stress in the BDL group play a base role in the pathogenesis of cholestasis-induced organ injury [37].

On the other hand, administration with Ovothiol-A orally caused a significant decrease $(p<0.5)$ in MDA and NO levels and a significant increase in GSH, CAT, GST, and SOD levels (Table 3). Ovothiol-A belongs to thiohistidines,ood nucleophiles and reducers, which may shield cells from reactive oxygen and nitrogen species [38]. In addition, biological systems quickly absorbed ovothiol A, resulting in elevated glutathione levels, most likely due to the synthesis of reduced Ovothiol A. [32].

Table 2. Protective effect of Ovothiol A on oxidative stress parameters on the liver of bile duct ligated rats.

\begin{tabular}{c|c|c|c}
\multirow{2}{*}{ Parameter } & \multicolumn{2}{|c}{ Groups } & Ovothiol A \\
\cline { 2 - 4 } & Sham & $1.31 \pm 0.18^{\mathrm{b}}$ & $0.97 \pm 0.04^{\mathrm{ab}}$ \\
\hline MDA (nmol/g. tissue) & $0.87 \pm 0.07^{\mathrm{a}}$ & $922.20 \pm 105.67^{\mathrm{b}}$ & $621.77 \pm 26.04^{\mathrm{a}}$ \\
\hline $\mathrm{NO}(\mu \mathrm{mol} /$ g. tissue $)$ & $610.35 \pm 67.30^{\mathrm{a}}$ & $0.68 \pm 0.02^{\mathrm{a}}$ & $1.04 \pm 0.06^{\mathrm{b}}$ \\
\hline GSH $(\mathrm{mg} / \mathrm{g}$. tissue $)$ & $1.14 \pm 0.06^{\mathrm{b}}$ & $230.86 \pm 29.76^{\mathrm{a}}$ & $367.25 \pm 40.79^{\mathrm{ab}}$ \\
\hline CAT (U/min.) & $519.30 \pm 74.68^{\mathrm{b}}$ & $0.63 \pm 0.12^{\mathrm{a}}$ & $0.92 \pm 0.08^{\mathrm{a}}$ \\
\hline GST $(\mu \mathrm{mol} /$ g. tissue) & $3.17 \pm 0.96^{\mathrm{b}}$ & $25.74 \pm 0.99^{\mathrm{a}}$ & $28.89 \pm 1.80^{\mathrm{ab}}$
\end{tabular}

Values are given as mean \pm SE for 7 rats in each group. Each value not sharing a common letter superscript is significantly different $(\mathrm{p}<0.05)$.

\subsection{Histopathological examination of the liver (hematoxylin \& eosin stain).}

The control group showed the normal histological structure of the hepatic lobules (Figure 1A) with hepatocytes arranged in a radiating hepatic cord from the central veins to the portal triads that compressed branches of the hepatic artery, hepatic portal vein, and bile duct (Figure 1B). The model group's bile duct ligation (BDL) resulted in severe histopathological alterations in the hepatic parenchyma. The BDL triggered liver fibrosis with the proliferation of the bile duct epithelium (Figure 1C) and mononuclear inflammatory cells infiltration 
(Figures 1D \&1E). Thick fibrous strands were extending from the portal triads towards the hepatic lobules (Figure 1F). Ovothiol-A improved the adverse effect of BDL. The liver sections showed a marked reduction in the bile duct proliferation noticed in a few sections compared to the model group (Figure $1 \mathrm{G}$ ) with apparently normal hepatic lobules in most examined sections (Figure 1H).
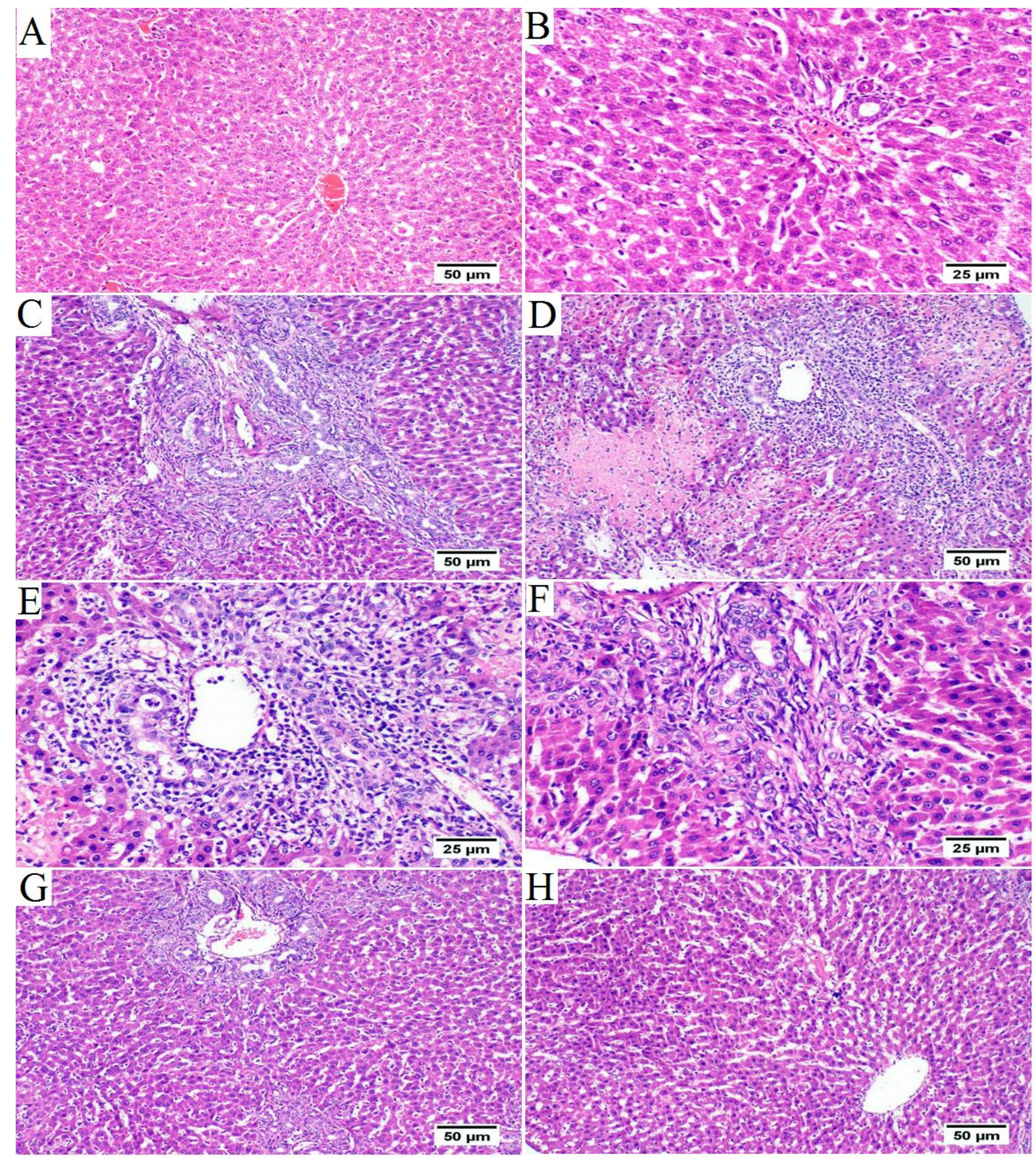

Figure 1. Liver tissues from control, BDL, and Ovothiol-A groups (H\&E).

\subsection{Histopathological examination of the liver (Masson Trichrome stain).}

The BDL- induced liver fibrosis was investigated in rats using MTC stain. The Control group showed normal fine strands of collagen surrounding the central veins (Figure 2A). The major blood vessels in the portal triads (Figure 2B), along with the normal architecture of hepatic lobules, showed no fibrous deposition existed in the hepatic parenchyma. Meanwhile, BDL triggered the excessive accumulation of collagen bundles in the portal triads adjacent to 
the blood vessels and proliferating bile ducts (Figure 2C). Extension of the fibrous tissue was detected in most stained sections that replaced the affected hepatocytes (Figure 2D). The treated group with Ovothio-A ameliorated the degree of hepatic fibrosis that formed by BDL. The MTC stain showed limited collagen deposition in the portal areas (Figure 2E) and scarce bundles in some hepatic lobules (Figure 2F).

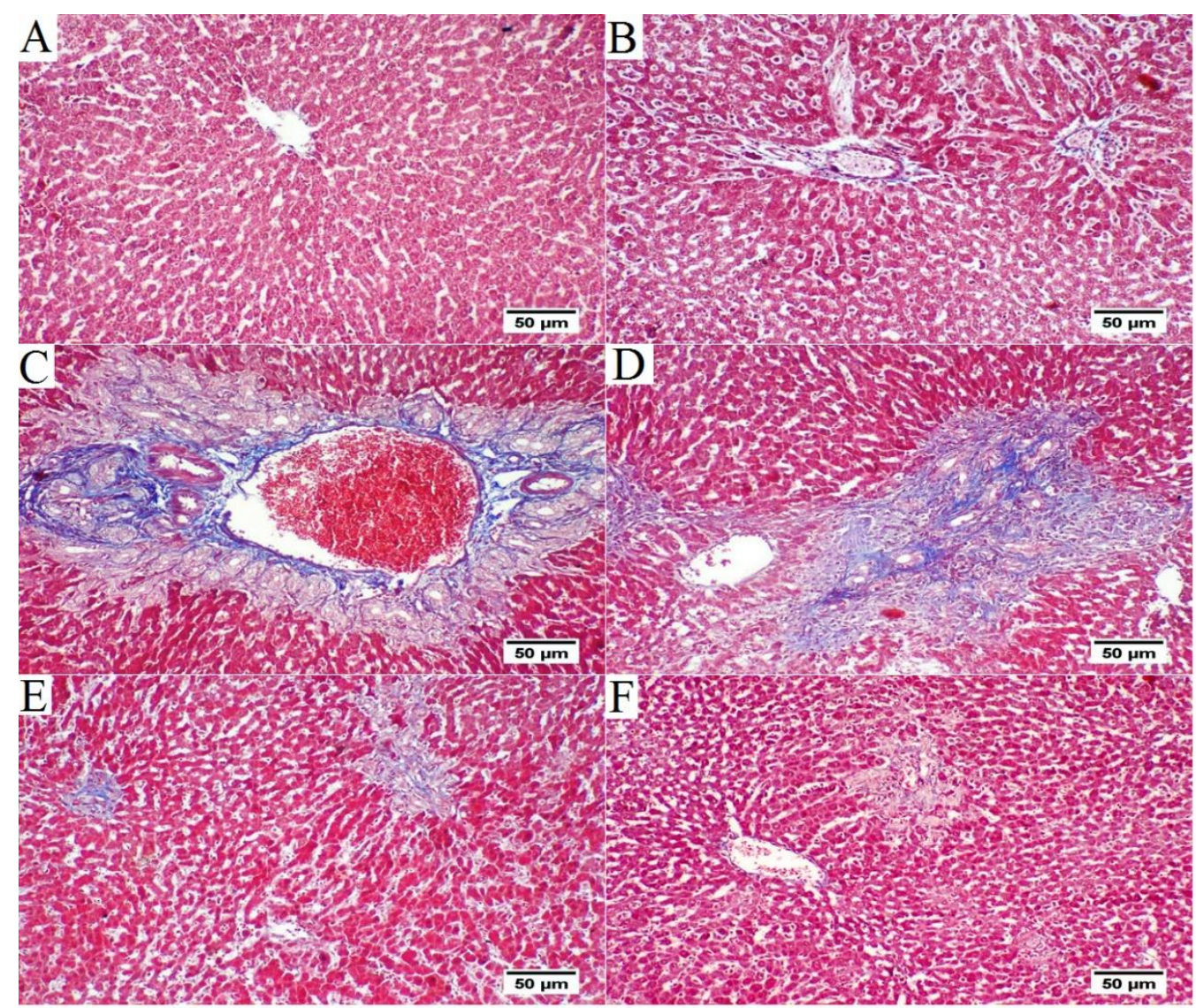

Figure 2. Liver tissue from control, BDL, and Ovothiol-A groups (MTC).

\subsection{The relative fibrosis area.}

The relative fibrosis area of BDL showed a significant increase in the BDL-group compared to control and Ovothio-A groups. Also, a significant difference was detected between the control and Ovothio-A groups at $\mathrm{p} \leq 0.05$ that scored 0.55 and 3.05 , respectively (Figure 3).

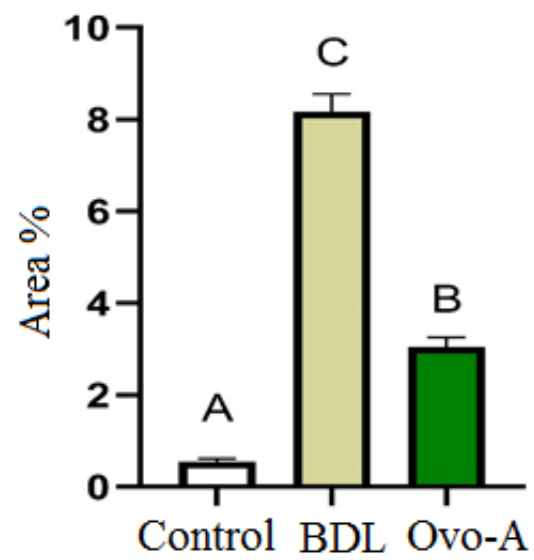

Figure 3. Changes in the percentage of fibrosis area percent among the groups; Values expressed as means \pm standard error $*(\mathrm{P}$-value $\leq 0.05), \mathrm{A}, \mathrm{B}$, and $\mathrm{C}$ indicate significant differences between values. 


\section{Conclusions}

The current study revealed the protective effect of Ovothiol-A against cholestasis induced by bile duct ligation in rats. The anti-fibrotic mechanisms of Ovothiol-A include inhibition of lipid peroxidation, restoration of antioxidant system activity, prevention of dyslipidemia, suppressing inflammation, and improving synthetic liver function.

\section{Funding}

No funding sources.

\section{Acknowledgments}

The authors extend their appreciation to the Deanship of Scientific Research at Cairo University, Egypt, for supporting the current work.

\section{Conflicts of Interest}

The authors declare no conflict of interest.

\section{References}

1. Karpen, S.; Kelly, D.; Mack, C.; Stein, P. Ileal bile acid transporter inhibition as an anticholestatic therapeutic target in biliary atresia and other cholestatic disorders. Hepatol Int 2020, 14, 677-689, https://doi.org/10.1007/s12072-020-10070-w.

2. McKeown-Longo, P. J.; Higgins, J.P; Hyaluronan, Transforming Growth Factor $\beta$, and Extra Domain AFibronectin: A Fibrotic Triad. Advances in Wound Care. 2021, 10, 137-152, https://doi.org/10.1089/wound.2020.1192.

3. Tanwar, S.; Rhodes, F.; Srivastava, A.; Trembling, P. Rosenberg, W. Inflammation and fibrosis in chronic liver diseases including non-alcoholic fatty liver disease and hepatitis C. World J Gastroenterol 2020, 26, 109-133, https://dx.doi.org/10.3748\%2Fwjg.v26.i2.109.

4. Puche, J. E.; Saiman, Y.; Friedman, S. L. Hepatic stellate cells and liver fibrosis. Comprehensive Physiology 2013, 3, https://www.josorge.com/publications/Citations/Hepatol/017.pdf. .

5. Duspara, K.; Bojanic, K.; Pejic, J. I.; Kuna, L.; Kolaric, T.; Nincevic, V.; Smolic; Vcev, A.; Glasnovic, M.; Curcic, I. B.; Smolic, M. Targeting the Wnt Signaling Pathway in Liver Fibrosis for Drug Options: An Update. Journal of Clinical and Translational Hepatology 2021, https://dx.doi.org/10.14218/JCTH.2021.00065.

6. Mesalam, M.; Aldhumri, A.; Gabr, A.; Ibrahim, A.; Al-Mokaddem, K.; Abdel-Moneim , A.-M. E. Putative abrogation impacts of Ajwa seeds on oxidative damage, liver dysfunction and associated complications in rats exposed to carbon tetrachloride. Molecular Biology Reports 2021, 48, 5305-5318, https://doi.org/10.1007/s11033-021-06544-1.

7. Blunt, J. W.; Carroll, A. R.; Copp, B. R.; Davis, R. A.; Keyzers, R. A.; Prinsep, M. R. Marine natural products. Natural Product Reports 2018, 35, 8-53, https://doi.org/10.1039/C7NP00052A.

8. Altmann, K. H. Drugs from the oceans: marine natural products as leads for drug discovery. CHIMIA International Journal for Chemistry 2017, 71, 646-652, https://doi.org/10.2533/chimia.2017.646.

9. Sadek, S. A.; Hassanein, S. S.; Mohamed, A. S.; Soliman, A. M.; Fahmy, S. R. Echinochrome pigment extracted from sea urchin suppress the bacterial activity, inflammation, nociception, and oxidative stress resulted in the inhibition of renal injury in septic rats. Journal of food biochemistry 2021, 2021, e13729, https://doi.org/10.1111/jfbc.13729.

10. Brancaccio, M. Biological Roles and Pharmacological Potentials of Marine 5Thiohistidine Compounds. PhD thesis The Open University 2021, https://doi.org/10.21954/ou.ro.00012914. 
11. Milito, A.; Castellano, I.; Burn, R.; Seebeck, F.P.; Brunet, C.; Palumbo, A. First evidence of ovothiol biosynthesis in marine diatoms. Free Radical Biology and Medicine 2020, 152, 680-688, https://doi.org/10.1016/j.freeradbiomed.2020.01.010.

12. Russo, G.; Russo, M.; Castellano, I.; Napolitano, A.; Palumbo, A. Ovothiol isolated from sea urchin oocytes induces autophagy in the Hep-G2 cell line. Marine drugs 2014, 12 (7), 4069-4085, https://doi.org/10.3390/md12074069.

13. OECD, O. f. E. C.-o. a. D. Guidance Document on Acute Oral Toxicity Testing 420; Organization for Economic Co-operation and Development: 2008, https://ntp.niehs.nih.gov/iccvam/suppdocs/feddocs/oecd/oecd_gl420.pdf.

14. Vogel, G. H.; Vogel, W. H. Drug discovery and evaluation. In Pharmacological Assays, 2nd ed.; Springer: Germany, 2002, pp 936-944, https://link.springer.com/referencework/10.1007/3-540-29837-1.

15. Mohamed, A. S.; Hosney, M.; Bassiony, S.; Hassanein, S. S.; Soliman, A. M.; Fahmy, S. R.; Gaafar, K. Sodium pentobarbital dosages for exsanguination afect biochemical, molecular and histological measurements in rats. Scientific Reports 2020, 10, 378, https://doi.org/10.1038/s41598-019-57252-7.

16. Lotfy, B. M.; Mousa, M. R.; El-Shehry, M. S.; Ahmed, S. H.; Ali, S. B.; Al Shawoush, A. M.; Mohamed, A. S. (2022). Therapeutic Potency of Gallium verum Extract on Ethanol-Induced Gastric Ulcer in Rats. Biointerface Research in Applied Chemistry, 2022, 12, 6010- 6020, https://doi.org/10.33263/BRIAC125.60106020.

17. Mohamed, A. S. Echinochrome Exhibits Antitumor Activity against Ehrlich Ascites Carcinoma in Swiss Albino Mice. Nutrition and Cancer 2021, 73, 124-132, https://doi.org/10.1080/01635581.2020.1737152.

18. Mohamed, A. S.; Mahmoud, S. A.; Soliman, A. M.; Fahmy, S. R. Antitumor activity of saponin isolated from the sea cucumber, holothuria arenicola against ehrlich ascites carcinoma cells in swiss albino mice. Natural product research 2021, 35, 1928-1932, https://doi.org/10.1080/14786419.2019.1644633.

19. Polidoro, M. A.; Ferrari, E.; Marzorati, S.; Lleo, A.; Rasponi. Experimental liver models: From cell culture techniques to microfluidic organs-on-chip. :Liver international 2021, 41, 1744-1761, https://doi.org/10.1111/liv.14942.

20. Tomur, A.; Kanter, M.; Gurel, A.; Erboga, M. The efficiency of CAPE on retardation of hepatic fibrosis in biliary obstructed rats. Mol. J. Histol. 2011, 42, 451-458, https://doi.org/10.1007/s10735-011-9350-6.

21. Munakarmi, S.; Chand, L.; Shin, H.; Jang, K.; Jeong, Y. Indole-3-Carbinol Derivative DIM Mitigates Carbon Tetrachloride-Induced Acute Liver Injury in Mice by Inhibiting Inflammatory Response, Apoptosis and Regulating Oxidative Stress.. International Journal of Molecular Sciences 2020, 21, 2048, https://doi.org/10.3390/ijms21062048.

22. El-Sisi, A. A.; Fahmy, S. R.; El-Desouky, M. A.; El-Tawil, O.; Mohamed, A. S.; El-Sherif, A. A. Protective roles of novel thiosemicarbazone derivatives on hepatotoxicity and nephrotoxicity induced by cadmium chloride in rats. Acta Poloniae Pharmaceutica - Drug Research 2021, 78, 193-203, https://www.ptfarm.pl/en/wydawnictwa/czasopisma/acta-poloniae-pharmaceutica/110/-/29032.

23. Singh, P.; Khan, S. Prevalence of jaundice based on liver function test in western nepal. Bali Medical Journal (Bmj) 2013, 2, https://ojs.unud.ac.id/index.php/bmj/article/view/6763.

24. Helal, E.; Abd El-Wahab, S.; Zedan, G.; Sharaf, A. Effect of Zingiber officinale on fatty liver induced by oxytetracycline in albino rats. The Egyptian Journal of Hospital Medicine 2012, 46, 26-42, https://dx.doi.org/10.21608/ejhm.2012.16354.

25. Copple, B. L.; Jaeschke, H.; Klaassen, C. D. Oxidative stress and the pathogenesis of cholestasis. Semin. Liver Dis 2010, 30, 195-204, https://doi.org/10.1055/s-0030-1253228.

26. Singh, K. Evaluation and interpretation of biomarkers of liver diseases. Int. J. Res. Health Sci. 2013, 1, 213 223, https://ijrhs.org/sites/default/files/IntJResHealthSci-1-3-213.pdf.

27. Akter, S.; Shekhar, H. U.; Akhteruzzaman, S. Application of Biochemical Tests and Machine Learning Techniques to Diagnose and Evaluate Liver Disease. Advances in Bioscience and Biotechnology 2021, 12 (6).

28. Saraswat, B.; Visen, P. K.; Patnaik, G. K.; Dhawan, B. N. Anticholestic effect of picroliv, active hepatoprotective principle of Picrorhiza kurroa, against carbon tetrachloride induced cholestasis. Indian J. Expt. Biol 1993, 31, 316-371, https://pubmed.ncbi.nlm.nih.gov/8359830/. 
29. Zajic, S.; Damnjanovic, Z.; Stojanovic, M.; Visnjic, M.; Dencic, S.; Ilic, D.; Sokolovic, D. Biochemical markers in patients with extrahepatic cholestasis. Acta Medica Medianae 2007, 47, 5-12, https://www.researchgate.net/publication/234129481_Biochemical_Markers_In_Patients_With_Extrahepat ic_Cholestasis.

30. Soliman, A. M.; Marie, M.-A. S.; Saleh, H. M.; Mohamed, A. S. Assessment of sepia ink extract role against. The Journal of Basic \& Applied Zoology 2014, 67, 173-181. https://doi.org/10.1016/j.jobaz.2014.04.001.

31. Younes, R. N.; Vydelingum, N. A.; Derooij, P.; Scognamiglio, F.; Andrade, L.; Posner, M. C.; Brennan, M. F. Metabolic alterations in obstructive jaundice: Effect of duration of jaundice and bile-duct decompression. HPB Surgery 1991, 5, 35-48, https://doi.org/10.1155/1991/27457.

32. Castellano, I.; Di Tomo, P.; Di Pietro, N.; Mandatori, D.; Pipino, C.; Formoso, G.; Napolitano, A.; Palumbo, A.; Pandolfi, A. Anti-Inflammatory Activity of Marine Ovothiol A in an In vitro Model of Endothelial Dysfunction Induced by Hyperglycemia. Oxidative Medicine and Cellular Longevity 2018, 2012, 2087373, https://doi.org/10.1155/2018/2087373.

33. Fang,; Luo; Ke; Liu; Yin; Yao; Feng; Huang; Zheng; Fan. Polydatin protects against acute cholestatic liver injury in mice via the inhibition of oxidative stress and endoplasmic reticulum stress. Journal of Functional Foods 2019, 55, 175-183, https://doi.org/10.1016/j.jff.2019.02.029.

34. Mamdouh, S.; Mohamed, A.S.; Mohamed, H.A; Fahmy, W.S. Zn contamination stimulate agonistic behavior and oxidative stress of crayfishes (Procambarus clarkii). Journal of Trace Elements in Medicine and Biology. 2022, 69, 126895, https://doi.org/10.1016/j.jtemb.2021.126895.

35. Muriel, P.; Suarez, O.; Gonzalez, P.; Zuñiga, L. Protective effect of S-adenosyl-1-methionine on liver damage induced by biliary obstruction in rats: a histological, ultrastructural and biochemical approach. $J$ Hepatol. 1994, 21, 95-102, https://doi.org/10.1016/s0168-8278(94)80143-6.

36. Jung, K.; Kwak, M. The Nrf2 system as a potential target for the development of indirect antioxidants. Molecules 2010, 15, 7266-7291, https://doi.org/10.3390/molecules15107266.

37. Grattagliano, I.; Oliveira, P. J.; Vergani, L.; Portincasa, P. Oxidative and Nitrosative Stress in Chronic Cholestasis. Liver Pathophysiology, Elsevier 2017, 225-237, https://doi.org/10.1016/B978-0-12-8042748.00017-5.

38. Castellano, I.; Seebeck, F. P. On ovothiol biosynthesis and biological roles: from life in the ocean to therapeutic potential. Natural product reports 2018, 35, 1241-1250, https://pubs.rsc.org/en/content/articlelanding/2018/np/c8np00045j/unauth. 